\title{
Sobre fronteras, sueños y encrucijadas. Una reflexión a partir de los tres últimos grandes libros sobre Chiapas
}

\author{
Federico Anaya Gallardo
}

ANTONIO GARCÍA DE LEÓN, 2002

Fronteras interiores. Chiapas:

una modernidad particular

Océano, México, 337 pp.

JAN DE VOS, 2002

Una tierra para sembrar: historia reciente de la selva lacandona (1950-2002)

FCE, CIESAS, México, 505 pp.

JUAN PEDRO VIQUEIRA, 2002

Encrucijadas chiapanecas. Economía, religión e identidades

Tusquets, El Colegio de México, México, 527 pp.

FEDERICO ANAYA GALLARDo: Doctorante en ciencias políticas por la Universidad de Georgetown.

Desacatos, núm. 12, otoño 2003, pp. 177-185.
【 a fascinación occidental por continuos desengaños, no agota sus entusiasmos. Los primeros conquistadores, engreídos por sus triunfos en los altiplanos mexicano y oaxaqueño, sin éxito, buscaron nuevas glorias en sus sierras, valles y cañadas. Un siglo más tarde, un alcalde mayor de San Cristóbal fundó en su selva oriental un "Reino de Próspero," acaso en imitación del exiliado duque-mago de Shakespeare. Casi al mismo tiempo, un fraile apóstata inglés convencía a Cromwell y a sus cabezas cuadradas de que Chiapas sería una fácil conquista y la base segura de un imperio americano para los puritanos... sueño del que sólo se concretó la Jamaica inglesa.

Durante todo el siglo XIX, las historias de ciudades de piedra perdidas en sus junglas fascinaron a historiadores, arqueólogos y espías, quienes, como Desiré de Charnay, atravesaron su territorio en busca de maravillas y redactaron informes confidenciales para sus gobiernos, cuyos proyectos 
imperiales son ahora presos de archivos polvosos y pasión de historiadores.

A fines de la década de 1920, el anarquista Bruno Traven aseguraba que en Chiapas se había gestado la primera humanidad y escribía entusiasmado que, al amparo de la revolución callista, "en el palacio [de Tuxtla Gutiérrez] tiene lugar diariamente, como en ningún otro lugar del continente, un proceso que anuncia una etapa del todo nueva en la historia de la humanidad"1 (sic que se enternece con la inocencia de los solidarios).

Treinta años más tarde, los cristianos evangélicos llegaron a Chiapas con un entusiasmo tal que intrigaba e inquietaba a la laica y callada Roberta Montagú. ${ }^{2}$ Poco después, la Iglesia católica halló en las cañadas orientales a nuevos israelitas que huyendo de la opresión del faraón capitalista buscaban la tierra prometida de la liberación. Al mismo tiempo, los antropólogos marxistas imaginaron que en sus montañas y cafetales echaría raíz la nueva revolución que sacaría a México de su atraso secular.

Un poco después, los guerrilleros de las Fuerzas de Liberación Nacional encontraron en las últimas selvas la esperanza final de una postrera opción

1 B. Traven, Tierra de primavera, Conaculta, México, Mirada viajera, 1996. Traducción castellana del original alemán titulado Land des Frühlings, Büchergilde Gutenberg, Frankfurt am Main, 1982, por Angélica Scherp. Prólogo de Alberto Vital, pp. 311-312.

2 Roberta Montagú, "La ranchería Yocnahab (primer libro de notas, 1957)", en Mario Humberto Ruz (ed.), Los legítimos hombres. Aproximación antropológica al grupo tojolabal, 4 vols., UNAM-IIFILOL-CEM, México, 1986, 4: 126236.

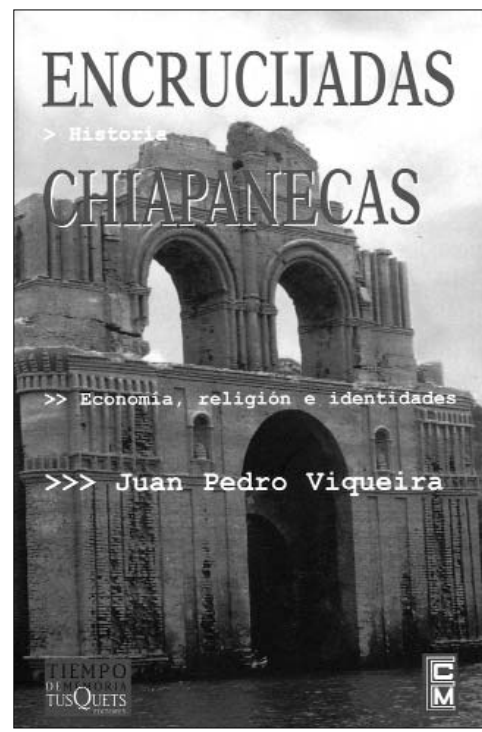

simultáneamente las tres piezas.

Hace unos pocos años, Jan de Vos elogiaba la aparición del libro de Carmen Legorreta, Religión, política y guerrilla en Las Cañadas de la Selva Lacandona, ${ }^{3}$ pues en su opinión era indispensable que quienes habían sido actores del drama chiapaneco moderno dieran a conocer al público sus opiniones y visiones acerca de su aventura. Legorreta nos entregó la visión desencantada de los asesores de la Asociación Rural de Interés Colectivo Unión de Uniones (ARIC-UU) que habían imaginado a esa agrupación como un mecanismo eficaz de articulación de las comunidades campesinas armada. Y, luego de la brumosa y fría madrugada del 1 de enero de 1994, la humanidad toda sueña que en aquella lejana última frontera del sistemamundo, hombres y mujeres enfrentamos la encrucijada entre la debacle neoliberal y un mundo en el que quepan todos los mundos.

¿Demasiados sueños para tan humilde pedazo del mundo? Tal vez. Como sea, los entusiasmos chiapanecos han producido una gran bibliografía. Las últimas tres grandes piezas de ella son Fronteras interiores. Chiapas: Una modernidad particular, de Antonio García de León (Océano, 2002); Una tierra para sembrar sueños. Historia reciente de la selva lacandona, 19502000, de Jan de Vos (FCE-CIESAS, 2002); y Encrucijadas chiapanecas, economía, religión e identidades, de Juan Pedro Viqueira (Tusquets, 2002). Se trata de lecturas indispensables para quien desee desentrañar el nudo gordiano del Chiapas de hoy. Estos apuntes buscan sugerir cómo abordar de la Selva Lacandona con los proyectos de modernización auspiciados por los gobiernos neoliberales mexicanos. Poco después, al discutir en San Cristóbal de Las Casas el libro de Jean Meyer, Samuel Ruiz en San Cristóbal, ${ }^{4}$ en el que se recogieron varias voces para perfilar un primer retrato de la complejidad religiosa del Chiapas moderno y del papel de los católicos liberacionistas en ella, muchos defentemas aún no se han enfriado lo suficiente como para poder tratar de entenderlos.

Éste es un primer problema que enfrentará el lector de García de León, De Vos y Viqueira: ¿hasta qué punto podemos evaluar racionalmente los

\footnotetext{
${ }^{3}$ María del Carmen Legorreta Díaz, Religión, política y guerrilla en Las Cañadas de la Selva Lacandona, Cal y Arena, México, 1998. ${ }^{4}$ Jean Meyer, con la colaboración de Federico Anaya Gallardo y Julio Ríos, Samuel Ruiz en San Cristóbal, Tusquets, México, 2000.
} dieron la posición contraria: que estos 


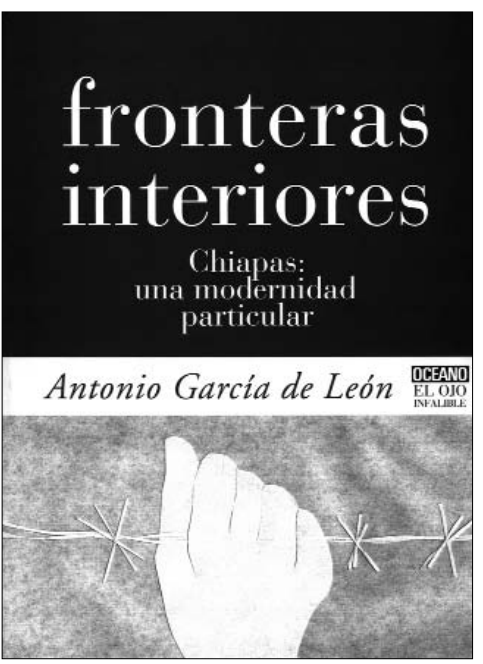

hechos ocurridos en Chiapas durante el último medio siglo? ¿No es demasiado pronto para analizar científicamente estos fenómenos sociales? Sin entrar en un debate filosófico sobre el punto, lo cierto es que en Chiapas ( $\mathrm{y}$ en todas partes) la vorágine de la vida contemporánea y la rapidez de las comunicaciones han puesto en el mismo lugar a reporteros, activistas y científicos sociales. Es una situación incómo$\mathrm{da}$, en la que estas tres especies de seres humanos debemos aprender a vivir juntas. El debate acerca de Chiapas (que hemos de dar simultáneamente en su cobertura periodística, en su praxis diaria y en su análisis científico) acaso nos permita crear un habitat común. Los tres libros reseñados aquí ayudan en esta labor.

\section{Quiénes escriben}

Al confrontar los textos de García de León, De Vos y Viqueira encontramos primero que nada contrastes persona- les, biográficos. Los dos primeros fueron actores de la gran movilización social que encabezó la diócesis católica de San Cristóbal de Las Casas entre 1960 y 2000. Antonio García de León, un pensador de izquierda marxista, llegó como lingüista y apoyó, entre otros proyectos, el Congreso Indígena de 1974. También trabajó en la primera época de la revista episcopal de don Samuel, llamada

\section{El Caminante.}

Jan de Vos arribó como sacerdote jesuita a la Misión de Bachajón y desarrolló su vocación de historiador buscando textos coloniales que sirvieran a la lucha de reivindicación agraria que Mardonio Morales SJ emprendió en la década de 1970 para proteger a sus feligreses tzeltales. Separado del sacerdocio, De Vos continuó ligado a Chiapas como historiador y a los jesuitas de la diócesis como amigo.

Juan Pedro Viqueira, en cambio, es un académico sin otra militancia que la misma ciencia social. Llegó a Chiapas en la década de 1980, luego de aquellas grandes movilizaciones; a él ya no lo exaltó el mismo fuego misionero que animaba a los anteriores intelectuales. De hecho, la única indignación que nos confiesa en su Encrucijadas... es la que le causa el ver cómo los intelectuales gobiernistas o de izquierda tergiversan los hechos históricos para apoyar acríticamente sus causas. Así, mientras García de León y De Vos nos hablan con el calor de los verdaderos creyentes en la causa de la liberación, Viqueira busca conciente y consistentemente tomar distancia de los entusiasmos que produce esa lucha.

\section{Cómo escriben}

Los acercamientos que cada uno de los autores utiliza son también distintos. García de León, siguiendo el método planteado en sus ya clásicos dos tomos de Resistencia y utopia, ${ }^{5}$ estudia las estructuras socioeconómicas de Chiapas y nos entrega una historia en la que los actores son movimientos sociales que realizan proyectos históricos en conflicto a lo largo de muchas generaciones. Es el primer libro que trata de hacer sentido general del medio siglo previo a la rebelión de 1994.

Este balance general permite entender el contexto de procesos específicos trabajados con detalle por otros autores en los últimos 20 años, como la ganaderización, estudiada por Fernández y Tarrío (1983), así como Villafuerte, García y Meza (1997); 6 la colonización de la Lacandonia investigada por Székely y Restrepo (1988) y Leyva y Ascencio (1996); ${ }^{7}$ y el espinoso asunto de la efectividad de la reforma agraria en Chiapas investigada por

\footnotetext{
${ }^{5}$ Antonio García de León, Resistencia y utopía. Memorial de agravios y crónica de revueltas y profecías acaecidas en la provincia de Chiapas durante los últimos quinientos años de su historia, 2 tomos, Era, Problemas de México, México, 1985 .

${ }^{6}$ Luis M. Fernández Ortíz y María Tarrío García, Ganadería y estructura agraria en Chiapas, UAM-Xochimilco, col. Ensayos, México, 1983; y Daniel Villafuerte Solís, María del Carmen García Aguilar y Salvador Meza, La cuestión ganadera y la deforestación. Viejos y nuevos problemas en el trópico y Chiapas, UNICACh/ CESMECA, Tuxtla Gutiérrez, 1997.

7 Miguel Székely e Iván Restrepo, Frontera agrícola y colonización, Centro de Ecodesarrollo, México, 1988; y Xóchitl Leyva Solano y Gabriel Ascencio Franco, Lacandonia al filo del agua, CIESAS/CIHMECH/UNAM/UNICACh/ FCE, México, 1996.
} 
Reyes, Moguel y Van der Haar. ${ }^{8}$ Luego de una década de suspiros, de alivios neoliberales por la caída del muro de Berlín, es reconfortante re-encontrar el lenguaje de "los antiguos" para describir "ciclos económicos", "periodos de crecimiento" y "crisis de interciclo". Reconfortante porque ese lenguaje, aunque viejo, permite hacer algo que se ha vuelto urgente en las ciencias sociales contemporáneas: encontrar causas estructurales de los conflictos que sacuden la sociedad.

Por su parte, Jan de Vos analiza estructuras ideológicas y su narración está formada por historias de vida que muestran cómo distintos actores concretos vivieron de manera diferente un mismo proceso social. Así, el autor utiliza ocho biografías o "sueños" como pretexto para presentar a otros

Lacandona del último medio siglo.

Cada uno de estos actores merecería un libro. El sueño de Pedro Vega, empresario chiapaneco que trató de consolidar las viejas concesiones madereras porfirianas en una explotación moderna donde se asociaba capital mexicano y estadounidense, nos sugiere un estudio del capitalismo dependiente mexicano. El sueño de Trudy Duby, la mujer del exploradoraventurero Franz Blom, nos invita a escribir la historia de los ecologismos internacional y mexicano. El sueño de Carlos Hernández, el colonizador tzotzil que salió de la región

\footnotetext{
${ }^{8}$ Eugenia Reyes Ramos, Reyna Moguel Viveros y Gemma Van der Haar, Espacios disputados: transformaciones rurales en Chiapas, UAM, México, 1998.
}

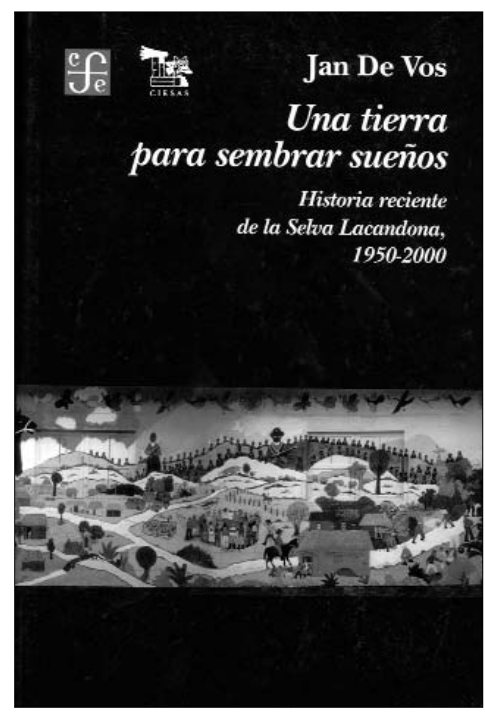

nado y comprensivo a los jóvenes indígenas que optaron por la vía armada antes de 1994.

A partir de la excusa que le presta cada una de estas biografías, De Vos presenta ocho particulares y específicas visiones de un mismo mundo en transformación: la Selva Lacandona. En su exposición, De Vos es fiel a uno de los más relevantes dictae de la teología de la liberación: la posición social del observador determina en buena medida su perspectiva epistemológica y por ello, lo que puede llegar a entender de la realidad que observa. Pero Jan da, de manera sencilla y elegante, un paso más allá: al presentarnos las visiones de varios actores, a quienes sabemos socialmente enfrentados (madereros y finqueros contra ecologistas; madereros, finqueros y ecologistas contra colonos indios; catequistas autóctonos y ariqueros contra neozapatistas; etc.), nos enseña que la realidad social es construida de modo paradójico por una pluralidad de actores y que la solución de los asuntos de cada día sólo puede encontrarse oyendo a todas esas voces, por más contradictorias y disonantes que sean.

Juan Pedro Viqueira investiga estructuras históricas, o más bien la gran estructura intrahistórica que Unamuno sugirió que subyace en el fondo de los fenómenos sociales específicos. El autor nos presenta una sucesión de documentos históricos a través de cuyas voces se va reconstruyendo la trama larga de los actuales eventos chiapanecos.

Durante las jornadas Chiapas: Investigaciones $y$ debates que el Seminario en Antropología Política de François 
Lartigue organizó en el Centro de Investigaciones y Estudios Superiores en Antropología Social (CIESAS) en febrero de 2003, Viqueira reconoció dos ventajas del historiador por sobre otros científicos sociales: la primera, que la mayor parte de sus potenciales informantes se han perdido. Así, mientras que muchos de los actores políticos (individuales y colectivos) del último medio siglo chiapaneco están vivos y podrían ser entrevistados, sólo algunas versiones de los conflictos sociales más antiguos fueron registradas en documentos escritos y aún menos de esas voces han sobrevivido al fuego, el agua, el viento y el olvido.

La segunda ventaja es que el historiador conoce el final de la historia que está narrando, situación imposible para el resto de los científicos sociales. Pero precisamente este último detalle, conocer los resultados de las luchas sociales, permite a la historia una perspectiva crítica que el resto de las ciencias sociales siempre encuentran problemática. Viqueira, entre otras cosas, es crítico de la idealización de la comunidad indígena realizada por periodistas, activistas y científicos sociales. Le molesta la "creación" de un pasado indio ideal pero irreal en el que, para explicar-justificar las luchas presentes, se borran los matices y se recalca únicamente la resistencia permanente de los amerindios nativos ante la inicua imposición occidental.

En cambio, los varios ensayos que conforman Encrucijadas... demuestran que la historia de las comunidades indias de Chiapas está jalonada por estrategias contradictorias de resistencia y colaboración con los conquistadores y colonizadores europeos. A través de los documentos que han sobrevivido, Viqueira puede comparar la efectividad de largo plazo de diversas estrategias, como la colaboración abierta de Chiapas y los chiapanecos; el acomodamiento interesado de los tzotziles de Zinacantán; o la colaboración-resistencia militar-adaptación de los tzeltales de Cancuc.

Paradójica ventaja de los materiales a disposición del historiador: siendo el azar y la fortuna quienes determinan qué sobrevive y qué se pierde, los ganadores de un determinado conflicto social no tienen la absoluta seguridad de que su visión del asunto sea la que sobreviva. Al analizar metódicamente los documentos dispersos, $\mathrm{y}$ al anotar con precisión las fuentes de las que se ha obtenido cada uno de los datos utilizados (a través de bien escritas y precisas notas de pie de página), las descripciones históricas de Viqueira permiten al lector interesado volver a revisar los materiales por su propia cuenta y, de esa manera, validar o demostrar falsas las tesis del autor.

De esta manera, la voluntaria ladinización de los chiapanecos, el lento desmembramiento del señorío de Zinacantán, los modos contradictorios en que se legitimaban los grupos que promovieron la rebelión de Cancuc en 1712, o la evolución de las finanzas en las cofradías de Chilón en los siglos XVII y XVIII permiten descubrir la complejidad de las estrategias indígenas de sobrevivencia, la increíble capacidad de adaptación del mundo indio a los cambios que le ha venido imponiendo la creación del sistemamundo occidental y la pluralidad interna de las comunidades.

Y, si como Viqueira dice, "la historia terminó ayer", es necesario concluir que la complejidad de indios y comunidades indias solamente ha podido aumentar en los últimos cincuenta años. De allí su crítica feroz a los estereotipos degradantes o idealizantes de la "comunidad tradicional indígena”. Parafraseando a Juan Pedro, lo único cierto, en materia de tradiciones, es que los indios (debíamos decir, los humanos) las aman tanto que las inventan continuamente.

\section{Por qué escriben (la oportunidad de publicar)}

En las jornadas Chiapas: Investigaciones $y$ debates, uno de los temas más candentes fue el de la oportunidad de la publicación de estos tres libros. El tema surgió alrededor del volumen de García de León pues, en opinión de muchos de los participantes en las jornadas, Fronteras interiores... es en realidad el tercer tomo de Resistencia y utopía... En efecto, a excepción de su último capítulo, Fronteras interiores... completa la historia de los movimientos sociales que los explotados de Chiapas iniciaran luego de la conquista española y que Resistencia y utopía... analiza sólo hasta la década de 1930.

Cuando Resistencia y utopía... se publicó en 1985, la historiografía chiapaneca moderna aún no contaba con muchas de sus mejores obras. Una obra como la de García de León, que 


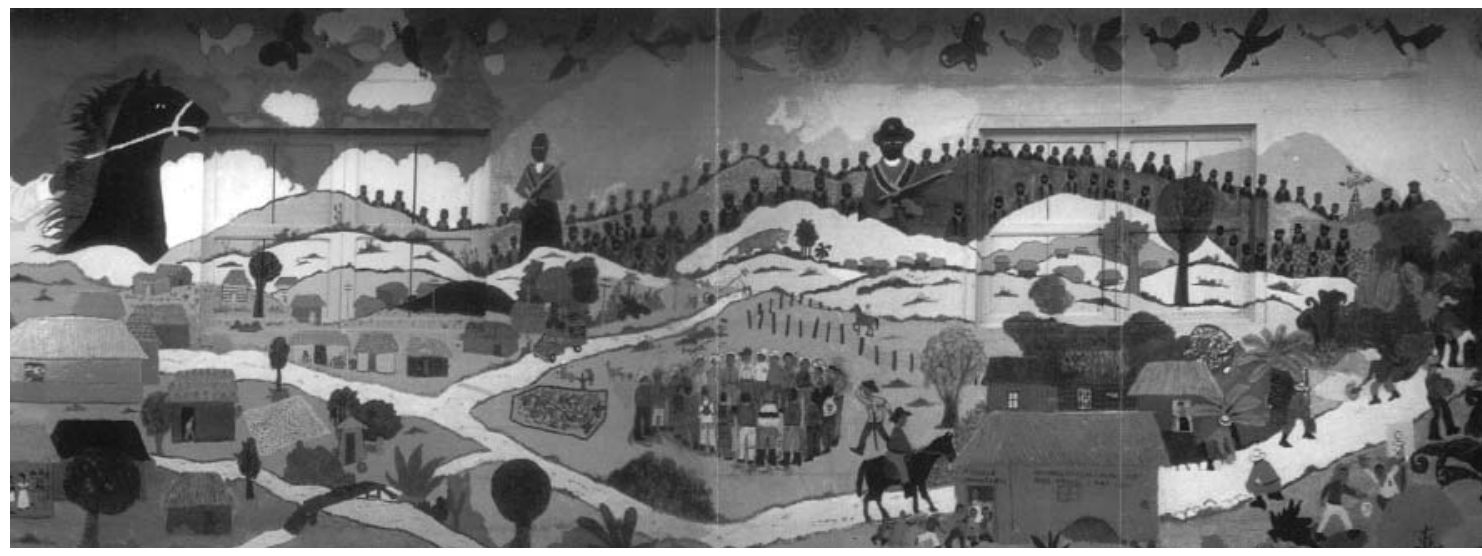

pretendía hacer un retrato total y un balance general de la historia de los movimientos sociales chiapanecos, era simplemente imposible desde el punto de vista estrictamente científico. Pero, desde el punto de vista social y político, esa obra era indispensable. Los nuevos movimientos sociales
1980 requerían un espejo histórico en el cual pudieran reflejar su rostro rebelde y fundar su esperanza de que, ahora sí, en esta ocasión, en esta vuelta de la historia, en este katún, la lucha popular alcanzaría la victoria final sobre los explotadores de siempre. Si acaso el historiador debiera haber callado, el militante político estaba obligado a escribir.

Felipe Castro, uno de los comentaristas del libro de Viqueira, sugirió recordar la categoría de publicista que se aplicaba a historiadores como Lucas Alamán, el Dr. Mora y Carlos María de Bustamante en el siglo XIX mexicano. Para ellos, el presente era parte de un continuum con el pasado y el futuro; y por lo mismo, escribir historia era participar en el debate político contemporáneo. Desde esta perspecti- va, García de León es un publicista de primer nivel, cuya lectura de la historia no es una joya para anticuarios sino punto de conflicto con otros participantes en el debate político.

Si las luchas de hace veinte años justificaron una aparición historiográficamente prematura de una obra general como Resistencia y utopía...; en 2002 el entuerto, a ratos inexplicable, del conflicto chiapaneco contemporáneo explica la publicación de Fronteras interiores... Sus primeros cinco capítulos son un rápido e indispensable update de actores y escenarios que Resistencia y utopía... había dejado en 1940. Esta actualización permite a su autor confrontar, en el capítulo final, a los actores políticos contemporáneos con quienes les precedieron en la lucha secular y juzgarlos implacablemente desde la plataforma del devenir centenario de la resistencia campesina e indígena chiapaneca.

En su intervención en las jornadas Chiapas: Investigaciones y debates, don Antonio fustigó duramente la incapacidad de la izquierda mexicana para hacer política real y efectiva, refugiándose siempre en planteamientos irrea- les que se justifican mejor en cuanto más radicales y "puros" sean. Este purismo, que ha afectado la causa zapatista durante el último decenio, ha terminado por aislarla y le impide consolidar y/o aprovechar las grandes victorias que obtuvo en los primeros años de la insurrección.

No menos publicistas son De Vos y Viqueira. De Vos, que nunca dejó el campo social de la diócesis católica de San Cristóbal de Las Casas, nos presenta en varios momentos las visiones encontradas y contradictorias que los colaboradores del obispo Samuel sostuvieron. En Samuel Ruiz en San Cristóbal, el que esto escribe había sugerido profundizar en el estudio de la disputa que jesuítas y dominicos sostuvieron en las décadas de 1970 y 1980 acerca del tipo de Iglesia que debía crearse entre los indígenas chiapanecos. De Vos nos presenta los términos de dicha disputa y analiza con detalle el pensamiento de quienes participaron en ella.

Una tierra para sembrar sueños es el primer texto muy difundido en el cual se describen analíticamente las propuestas del Catecismo Tzeltal redacta- 


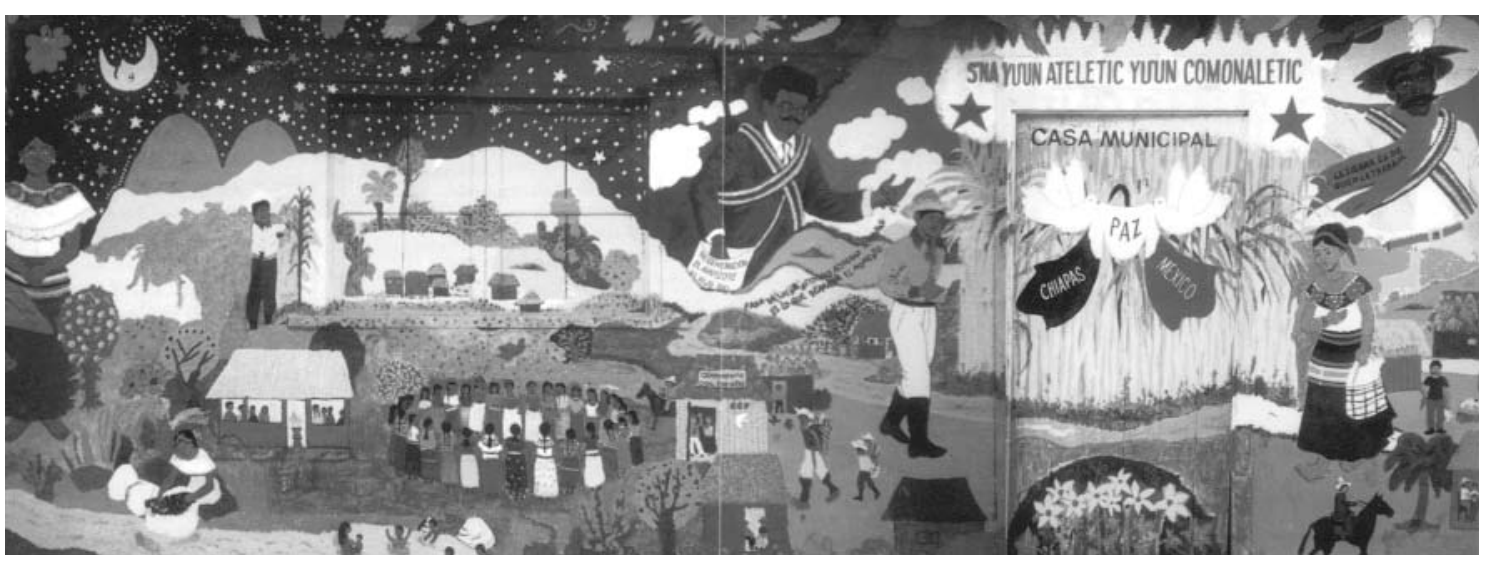

do entre 1972 y 1974 por los catequistas indios y los agentes de pastoral del obispo. De Vos pasa de la descripción a la crítica: se pregunta sistemáticamente cuál de los dos autores colectivos del Catecismo Tzeltal tuvo el control de la redacción. El avezado lector de textos históricos y compañero de luchas sugiere elegantemente que la intervención de los agentes de la pastoral fue mucho más determinante que las ideas surgidas de los corazones y las mentes de los indígenas.

Específicamente, De Vos retrata el crucial papel de Javier Vargas, religioso marista en la década de 1960, quien en aquellos años dirigió los primeros esfuerzos pastorales de la diócesis católica para inculturarse en las comunidades indias y que en la última década, desde una influyente organización civil ha continuado siendo una voz relevante en la política social de Chiapas. Ojalá que la versión de Vargas acerca de la compleja historia reciente de Chiapas esté algún día a disposición de los lectores.

Viqueira, el más joven de los autores reseñados, debiera ser el menos publicista del trío, dado su perfil de científico social riguroso y detallista. Paradójicamente, su condición científica es la que le ha empujado a volverse interlocutor en el espacio público generado por los acontecimientos chiapanecos. La Verdad, ese Santo Grial de la ciencia occidental moderna, es el fuego que enciende los entusiasmos de Juan Pedro.

Encrucijadas..., al contrario de las obras de García de León y De Vos, no es una pieza homogénea, escrita como un todo, sino una colección de ensayos que el autor había venido publicando en varios foros desde 1988 y con la cual busca resumir y consolidar sus opiniones sobre Chiapas. De los tres libros es el más difícil de leer, pues, partiendo de numerosos procesos históricos específicos que tuvieron lugar a lo largo de 500 años, el autor busca presentarnos un retrato verosímil del Chiapas actual. Empresa difícil. Lo fascinante es que ha tenido éxito.

Sucede que Viqueira no cree, como García de León, que los actores de la historia sean los movimientos sociales ni que existan proyectos históricos trans-generacionales que, más allá de los individuos, prosiguen su marcha.
No hay, pues, ninguna fe marxista en un devenir histórico antropomorfizado. Lo único que hay en la historia son hombres y mujeres concretos, la mayoría de ellos simples y sencillos, quienes, al modo de Rashomón, vieron cosas distintas en el mismo hecho cronológicamente datado. Por eso Viqueira no puede contestar en definitiva qué había detrás del petate de Cancuc en 1712. Pudo ser la profetiza tzeltal María Candelaria o una imagen de la Virgen María, o incluso un ídolo prehispánico con forma de jaguar.

Del mismo modo, los ensayos de Viqueira nos muestran cómo, simultáneamente, en el siglo XVIII las cofradías indias prosperaban en Tuxtla y sufrían en Chilón. Y, al revisar las tendencias poblacionales de largo plazo, cómo diversas regiones de Chiapas se han des-indianizado o re-indianizado en una misma época. Juan Pedro tiene un nombre para su propuesta: teoría de los desfases. Nos dice el autor: "la dinámica histórica (ya sea social o personal) nace y se expresa en los desfases: entre el grupo y la persona, la identidad y la cultura, el pasado y el presente" (p. 391). 
Los humanos tenemos la mala suerte de ser, a un tiempo, sujetos de nuestra propia historia y objetos de nuestro estudio de esa historia. Vivimos y nos vemos vivir simultáneamente. Y de la diferencia entre lo que somos y lo que, como observadores de nuestro propio devenir, desearíamos ser, nacen las tensiones que nos animan. Este tipo de reflexiones lleva a Viqueira al debate público, pues le indigna la manera en que las facciones suelen adulterar los discursos históricos para probar sus argumentos sin reconocer que no hay, jamás, una sola verdad sino muchas opiniones acerca de cada asunto.

\section{Lo que escriben los autores y lo que lee su público}

Ningún libro aparece en el vacío social. Los de García de León, De Vos y Viqueira son parte de un contexto tenso, muy cargado de expectativas y prejuicios. Fronteras interiores... ha sido poco reconocido y muy vilipendiado precisamente por esto. Los lectores no podían verlo solamente como el resultado de la erudición de don Antonio, sino que lo leyeron como el producto de quien fuera el coordinador de los asesores e invitados zapatistas en el diálogo de San Andrés. Por lo mismo, la revisión integral de la historia chiapaneca que hizo pasó prácticamente desapercibida en todos los círculos.

Nadie ha comentado el terrible aislamiento que debió existir en el Chiapas del medio siglo para que hoy no sea recordada una matanza como la ocurrida en La Trinitaria en 1955, en la que el general del ejército Agustín Mustieles, so pretexto de que medio millar de personas recorrían la región fronteriza ("levantados" les llamó el general, otros dijeron que era una peregrinación), mandó ejecutar a 87 personas, decapitar los cadáveres de los líderes y exponer sus cabezas por seis días en el cabildo del lugar (pp. 90-91). Lo que la audiencia de García de León deseaba leer era su postura personal frente al EZLN y no su lectura histórica de los procesos sociales chiapanecos entre 1940 y 2000. Así, su crítica al zapatismo en el último capítulo del libro prohijó escándalo y esa sección recibió el anatema de los verdaderos creyentes zapatistas.

Tristemente, la condenación parece extenderse a toda la obra. Acaso esto último fuera inevitable: el libro de García de León explicita el escenario social del que surgió el zapatismo chiapaneco moderno y confronta a éste actor político concreto con los movimientos sociales que, de acuerdo con la visión de la historia del autor (visión que comparten los zapatistas), habían venido construyendo dicho escenario. Es de entenderse que los actores políticos presentes se encuentren a disgusto cuando sus posiciones son confrontadas con los complejos procesos sociales que les antecedieron (y que en una lectura marxista, los determinaron). Uno nunca está a la altura de las expectativas de sus padres. Mucho menos cuando los padres de uno creen en un devenir histórico en el que es nuestro deber realizar las expectativas finales de la liberación revolucionaria.
Comparado con el escándalo que provocó García de León, Una tierra para sembrar sueños... fue recibida con regocijo académico y ecuanimidad política. Pero esta primera reacción es acaso engañosa. La Academia agradeció este libro porque Jan lo había anunciado desde 1988, al terminar Oro verde. ${ }^{9}$ Sería la última parte de su trilogía histórica regional sobre Lacandonia.

Los científicos sociales no necesitaban leer Una tierra para sembrar sueños... para aplaudirlo, pues confiaban en la calidad del autor. Acaso por ello no han caído en cuenta que, al hacer historia de hechos recientes, las opiniones de Jan implican deslindes muy claros y muy fuertes en los debates pastorales de la Diócesis de San Cristóbal de Las Casas y, por lo mismo, respecto de temas muy candentes, como el concepto de identidad india o el papel de la Iglesia en las organizaciones que nacieron en el periodo. Es decir, el libro fue recibido con ecuanimidad política porque nadie lo ha leído con atención en sus muchos detalles.

Aquí vale la pena comparar cómo García de León y De Vos tratan un mismo asunto, el de la corriente maoísta de Política Popular-Línea Proletaria (PP-LP). El primero, sin tapujos, lo califica como "proyecto piloto" del gobierno (p. 107), "ambicioso proyecto del Estado para neutralizar la radicalidad de varias movilizaciones obreras y campesinas" (p. 194), que buscaba "desprestigiar a las dirigencias de la

${ }^{9}$ Jan de Vos, Oro Verde. La conquista de la Selva Lacandona por los madereros tabasqueños, 1822-1949, FCE, México, 1988. 
'vieja izquierda' en nombre de 'las masas' y así descabezar al movimiento regional, orientándolo hacia metas productivistas y de 'política constructiva" (p. 189). Y según García de León, pese a un desencuentro inicial en 1977, "un sector importante (de la diócesis católica) siguió por años colaborando con Línea Proletaria y sus derivados, principalmente en Ocosingo y Tila, hasta 1994, por lo menos" (p. 193).

Jan de Vos aborda el mismo tema, sin calificativos políticos pero aportando más detalles. Explica cómo un grupo maoísta distinto y anterior a LP, llamado Unión del Pueblo, en estrecha colaboración con la diócesis a través de Javier Vargas, ayudó a formar en 1975 la unión de ejidos Quiptic Ta Lecubtesel, una de las organizacionesmadre de la actual ARIC (pp. 254-256). Explica luego cómo los éxitos de la Quiptic atrajeron a PP-LP en 1977; cómo la diócesis y esta nueva organización colaboraron por un tiempo, rompieron y cómo LP logró regresar más tarde al territorio de la diócesis (pp. 258-260).

Pero De Vos confirma algunos de los trazos de la descripción de García de León, pues los asesores de LP trajeron un "cambio notable... implantar una estrategia de mayor negociación con las autoridades" (p. 260), lo que reportó a las comunidades muchos éxitos debidos "en buena parte, a los servicios del fundador de Política Popular, Adolfo Orive, quien tenía excelentes relaciones en el mundo político y banquero de la capital del país" (p. 263). Al aportar más detalles acerca de estos procesos, Una tierra para sembrar sueños... causa menos escándalo pero cala mucho más profundo en el análisis de las polaridades políticas existentes en Las Cañadas zapatistas.

Finalmente, Encrucijadas... estaba destinado a causar escándalo no por las expectativas creadas por la trayectoria política de su autor ni por su contenido, sino por el campo social en que Viqueira se ha ido situando luego de 1994. En 1995, su insistencia en que los científicos sociales provean a los actores políticos de elementos "duros" que impidan la demagogia de las facciones lo llevó a publicar Chiapas, los rumbos de otra historia, ${ }^{10} \mathrm{y}$ en 1999 , "Los peligros del Chiapas imaginario" en el número inicial de Letras Libres. La primera publicación no causó problemas, pues la editaron instituciones académicas y, al parecer, los políticos prácticos nunca han considerado relevante ese tipo de ediciones. La segunda ubicó a Juan Pedro en el campo social de centro-derecha junto a Enrique Krauze.
Encrucijadas... fue recibida en este último contexto y, por ello, antes de ser leído, era ya piedra de escándalo entre la intelectualidad progresista. Lo anterior es una tragedia pues, de las tres obras aquí reseñadas, el libro de Viqueira es el aporte más complejo al estudio del Chiapas contemporáneo. Por una parte, ubica con rigurosidad los orígenes, las constantes y las pautas de la geopolítica chiapaneca. Por la otra, caracteriza con precisión cómo comunidades y líderes indios manipulan su identidad para adaptarse a circunstancias cambiantes. Que los involucrados en la praxis política ignoren estas aportaciones por prejuicio respecto de las intenciones del autor, no es solamente éticamente malo, es un error.

Decía Maquiavelo que "es dichoso aquél cuyo modo de proceder se haya en armonía con la calidad de las circunstancias, $y . .$. no puede menos que ser desgraciado aquél cuya conducta está en discordia con los tiempos" (El príncipe, XXV). Conocer circunstancias y tiempos es una tarea compleja, obras como las reseñadas ayudan mucho. Ojalá y sean muy leídas, muy comentadas y utilizadas por muchos en la praxis.
${ }^{10}$ Juan Pedro Viqueira y Mario Humberto Rus
(eds.), Chiapas, los rumbos de otra historia,
UNAM-IIFILOL-CEM/CIESAS/CESMECA/UDEG,

${ }^{10}$ Juan Pedro Viqueira y Mario Humberto Rus
(eds.), Chiapas, los rumbos de otra historia,
UNAM-IIFILOL-CEM/CIESAS/CESMECA/UDEG,

${ }^{10}$ Juan Pedro Viqueira y Mario Humberto Rus
(eds.), Chiapas, los rumbos de otra historia,
UNAM-IIFILOL-CEM/CIESAS/CESMECA/UDEG, México, 1995. 